Article

\title{
Integration of Seawater Pumped-Storage in the Energy System of the Island of São Miguel (Azores)
}

\author{
Christos S. Ioakimidis ${ }^{1,2,3, *}$ and Konstantinos N. Genikomsakis ${ }^{1(1)}$ \\ 1 ERA Chair ( ${ }^{*}$ Holder) 'Net-Zero Energy Efficiency on City Districts, NZED' Unit, Research Institute for \\ Energy, University of Mons, Rue de l'Epargne, 56, 7000 Mons, Belgium; \\ konstantinos.genikomsakis@umons.ac.be \\ 2 MIT I Portugal Program, Sustainable Energy Systems, Tagus Park, 2744-016 Porto Salvo, Portugal \\ 3 IN+, Department of Mechanical Engineering, Instituto Superior Técnico, (UTL), 1049-001 Lisbon, Portugal \\ * Correspondence: christos.ioakeimidis@umons.ac.be; Tel.: +32-(0)65-374-462
}

Received: 7 August 2018; Accepted: 26 September 2018; Published: 27 September 2018

check for updates

\begin{abstract}
This paper considers the case of São Miguel in the Azores archipelago as a typical example of an isolated island with high renewable energy potential, but low baseload levels, lack of energy storage facilities, and dependence on fossil fuels that incurs high import costs. Using the Integrated MARKAL-EFOM System (TIMES), a number of scenarios are examined in order to analyze and assess the potential benefits from the implementation of a seawater pumped-storage (SPS) system, in the absence or presence of electric drive vehicles (EDVs) under a grid-to-vehicle (G2V) approach. The results obtained show that the proposed solution increases the penetration of renewable energy in the system, thus reducing the dependence on fossil fuel imports and allowing, at the same time, for the deployment of EDVs as a promising environmentally friendly alternative to conventional vehicles with internal combustion engines.
\end{abstract}

Keywords: electric drive vehicles; energy storage; seawater pumped-storage; transportation

\section{Introduction}

Although the concept of pumped hydro energy storage (PHES) is not recent, there has been a renewed interest over the last years in systems of this type as a means of enabling better use of the fluctuating energy production from renewable and clean sources, while ensuring grid stability and securing energy supply [1]. The review study in [2] reports that PHES is the most suitable technology for small autonomous island grids and massive energy storage, however, the intermittent nature of renewable energy sources, such as wind, solar, wave or tidal, imposes new challenges on increasing their penetration in electricity systems (note: in the context of this paper, penetration of renewable energy sources refers to the percentage of demand covered by renewable energy in a certain region, normally on an annual basis) [3]. The commercial and technical maturity of PHES technology provides a cost-effective solution for large scale energy storage (>100 MW) [1], bringing the estimated total installed capacity worldwide to $150 \mathrm{GW}$ at the end of 2016, increased by approximately $6.4 \mathrm{GW}$ in that year [4].

PHES systems typically operate with low-cost off-peak or excess electricity to pump water from a lower to an upper reservoir (either natural or artificial) in order to use the stored potential energy of the water for electricity generation upon system demand [5]. These systems are characterized by round-trip efficiency in the range of $70-80 \%$, while figures reaching $87 \%$ are also reported in the literature [6]. Moreover, key features of the PHES systems include fast start-up time and high ramp rate. In Korea, for example, the PHES start-up time is $4 \mathrm{~min}$ and the ramp rate is ten to twenty times higher compared to that of combined cycle units, as reported in [7]. Hence, the introduction of PHES 
is particularly suitable for non-interconnected insular systems not only to increase the penetration of renewable energy sources, but also to tackle with the high cost of electricity production $[2,8]$. Indicatively, in a European context, the first hybrid systems that integrate pumped-storage with wind power were planned for construction in the islands of Ikaria, Greece, and El Hierro, Spain $[9,10]$. Considering that the operation of such systems in isolated islands may suffer from the lack of the required quantity of water, e.g., due to low annual rainfalls, the use of seawater pumped-storage (SPS) systems, where the sea plays the role of the lower reservoir, is proposed as the only feasible alternative to tackle with this issue [11,12].

Compared to traditional PHES systems that use fresh water, the storage medium in the SPS counterparts is seawater [12]. In detail, SPS systems can pump seawater directly from the sea, thus the construction of a lower reservoir is avoided [11], which further implies less land use and lower construction costs in this case. However, the use of seawater (instead of fresh water as in PHES systems) results in increased costs related to corrosion protection and the prevention of ground contamination from salt water [13]. In this regard, the costs of avoiding the construction of a lower reservoir in SPS systems compensate for the additional costs incurred to effectively deal with the corrosion and leakage effects [11]. Therefore, SPS systems comprise a solution for areas characterized by a lack of abundant natural fresh water [14].

Along these lines, a real-world implementation is the $30 \mathrm{MW}$ plant in Okinawa, Japan [15], while there are plans for larger facilities in Ireland $[2,9,16]$ and Hawaii $[16,17]$. A review of the relevant literature reveals that rather limited research efforts have focused on systems of this type. The authors in [18] examine the case of implementing an SPS system in São Miguel considering scenarios that combine different fuel prices and growth rates of electricity consumption. In this context, a stochastic model is proposed in [19] for optimally sizing a pumped-storage power plant in São Miguel. On the one hand, the benefits of increasing the integration of renewable energy resources in the power system of São Miguel are presented in [20], while on the other hand, the integration of electric drive vehicles (EDVs) in this insular power system is discussed in relevant energy modelling studies [21-24]. Specifically, the work in [21] discusses the potential revenues for EV owners in São Miguel from providing vehicle to grid (V2G) power, while the study in [22] examines the possibility of using the batteries of EDVs as an energy storage system for the island and the impact on the energy generation from renewable sources. The authors in [23] analyze EDV deployment scenarios for reducing the $\mathrm{CO}_{2}$ emissions and energy costs in isolated regions using São Miguel as a case study, while the authors in [24] consider additional scenarios with respect to the deployment of EDVs and the increase of electricity demand in the local energy system of São Miguel. Building upon these contributions, the present work employs The Integrated MARKAL-EFOM System (TIMES) to examine scenarios that combine the introduction of a SPS system in São Miguel with the deployment of EDVs. Hence, this work presents the results obtained from different scenarios with respect to the evolution of the local energy system compared to the aforementioned published works.

The rest of the paper is organized as follows: Section 2 provides an overview of the characteristics of São Miguel, along with the existing situation and future evolution of its energy system. Section 3 describes in detail the methodological framework for representing the energy system of São Miguel using the TIMES model generator, while the subsequent Section 4 presents the scenario results and discusses their significance. The last section summarizes and concludes the paper.

\section{Case Study: São Miguel, Azores}

\subsection{General}

São Miguel is located in the southern part of the group of nine volcanic islands that comprise the archipelago of Azores in the Atlantic Ocean, about $1360 \mathrm{~km}$ west of continental Portugal. It covers an area of $747 \mathrm{~km}^{2}$, spanning $64 \mathrm{~km}$ from east to west and $23 \mathrm{~km}$ from north to south, while having a population of roughly 130,000 [25]. The electric power system in São Miguel is autonomous, given that 
there is neither a power connection to the continental grid of Portugal nor an interconnection among the Azores islands, as a result of their geographic isolation and dispersion. Hence, São Miguel heavily relies on the import of fossil fuels, while it consumes $56 \%$ of total primary energy of the nine islands in the archipelago of Azores [18].

\subsection{Electricity Production and Consumption}

The electricity sector in São Miguel consumes approximately 35\% of total primary energy, being responsible for significant imports of thick fuel oil [26]. Electricity production is characterized by a low diversity of available sources, as shown in Figure 1 for the year 2007: fuel oil is the major energy source, followed by renewable energy sources, mainly geothermal, and to a lesser extent small hydro and biomass [27]. The installed capacities of the relevant power plants are presented in Table 1.

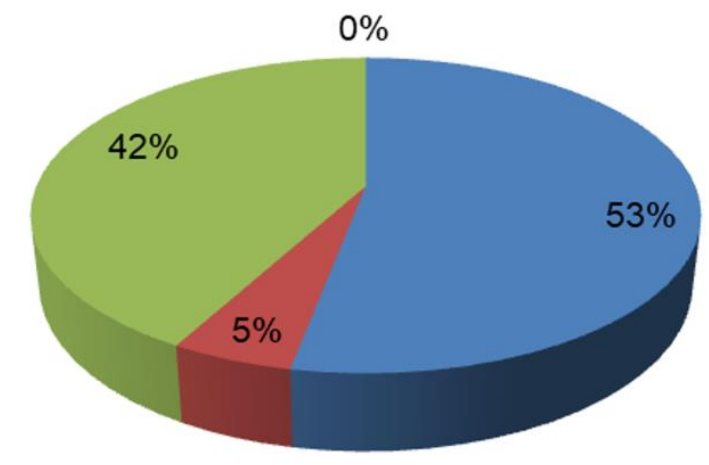

Total production: $429 \mathrm{GWh}$

$$
\text { - Fuel oil } \square \text { Hydro } \square \text { Geothermal } \square \text { Biomass }
$$

Figure 1. Electricity production in São Miguel, in 2007.

Table 1. Power plants in São Miguel, in 2007.

\begin{tabular}{ccc}
\hline Energy Source & Power Plant & Capacity (MW) \\
\hline Fuel oil & Caldeirão & 115 \\
Geothermal & Pico Vermelho & 10 \\
& Ribeira Grande & 14 \\
Hydro & Several plants & 5 \\
\hline
\end{tabular}

Figure 2 clearly shows the high share of commerce/services and domestic sector in electricity consumption, followed by industries and agriculture, as well as public services and public lighting with a small percentage of $8 \%$ and $4 \%$, respectively. The electricity consumption profile presents similar patterns throughout the year as indicated in Figure 3 [28], with the main difference being on the time of day where the maximum demand occurs on weekdays, namely during morning and night hours for the summer and winter, respectively. It is noted that the electricity consumption over the course of the day is higher on weekdays, followed by that of Saturdays and Sundays, either in summer or winter, while in all cases the lowest consumption is observed during the first hours of the day. 


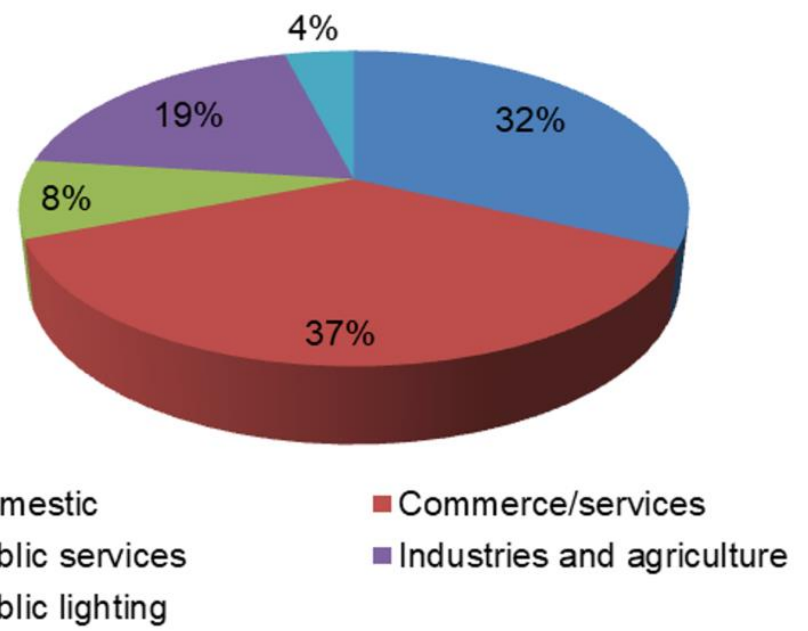

Figure 2. Percentage breakdown of electricity consumption by sector of activity in São Miguel.

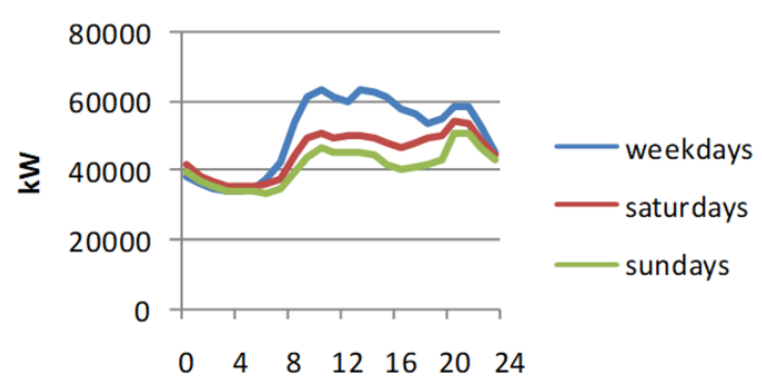

(a)

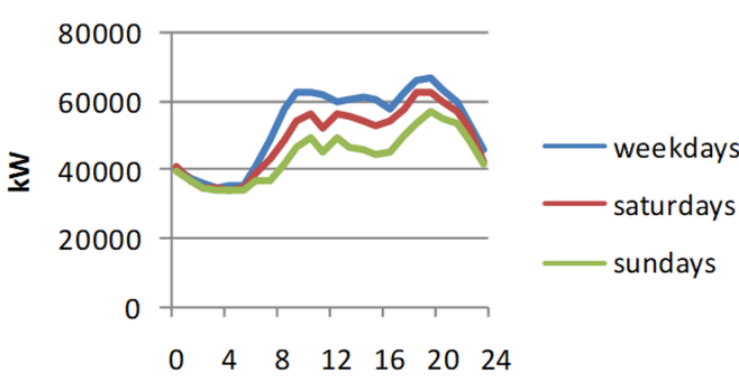

(b)

Figure 3. Electricity load profiles in São Miguel during (a) summer, and (b) winter, in 2007.

\subsection{Role of Pumped-Storage and Site Selection}

PHES systems enable utility-scale energy storage for many hours or even days [29] and combine flexible start/stop capabilities with quick response time, implying that they are particularly suitable for shifting electricity produced from renewable and intermittent sources in low demand periods to peak hours, matching supply with system demand, as well as providing frequency regulation and voltage control services [30]. Furthermore, the energy storage contributes to the reduction of distribution costs and the minimization of losses from power disruptions, while the civil construction works of the lower reservoir are avoided in the case of pumping seawater directly from the sea [11,31,32]. In general, a key challenge is the selection of a suitable site having certain physical characteristics, typically with two reservoirs separated by a minimum distance of $100 \mathrm{~m}$ and in the vicinity of the power grid, preferably close to existing power lines with proper voltage and available transmission capacity. Considering that the construction of PHES systems requires extensive civil engineering works, significant environmental concerns may be raised with regard to the impact of potential interventions in areas of particular scenic importance [33].

Being a volcanic island, São Miguel has several high and steep elevations (the three main ones have heights of around $800 \mathrm{~m}$ ) which could be used to build a PHES facility, based either on artificial reservoirs or existing natural lagoons. Figure 4 shows some possible sites where PHES plants could be built, either next to a river or close to the sea according to the study in [34]. The economic benefits, as well as the performance of PHES facilities in the context of life-cycle assessment (LCA) have been well documented in the literature $[1,5,35]$, while the proposed SPS technology has already been installed and tested successfully in Okinawa, Japan [36,37]. SPS projects have several advantages compared to their river-based counterparts, including the use of an infinite resource, lower environmental impact, 
smaller flooded areas and smaller-scale civil engineering works, but they require higher operations and maintenance $(\mathrm{O}$ and $\mathrm{M})$ costs due to corrosion, algae, and sea organisms.

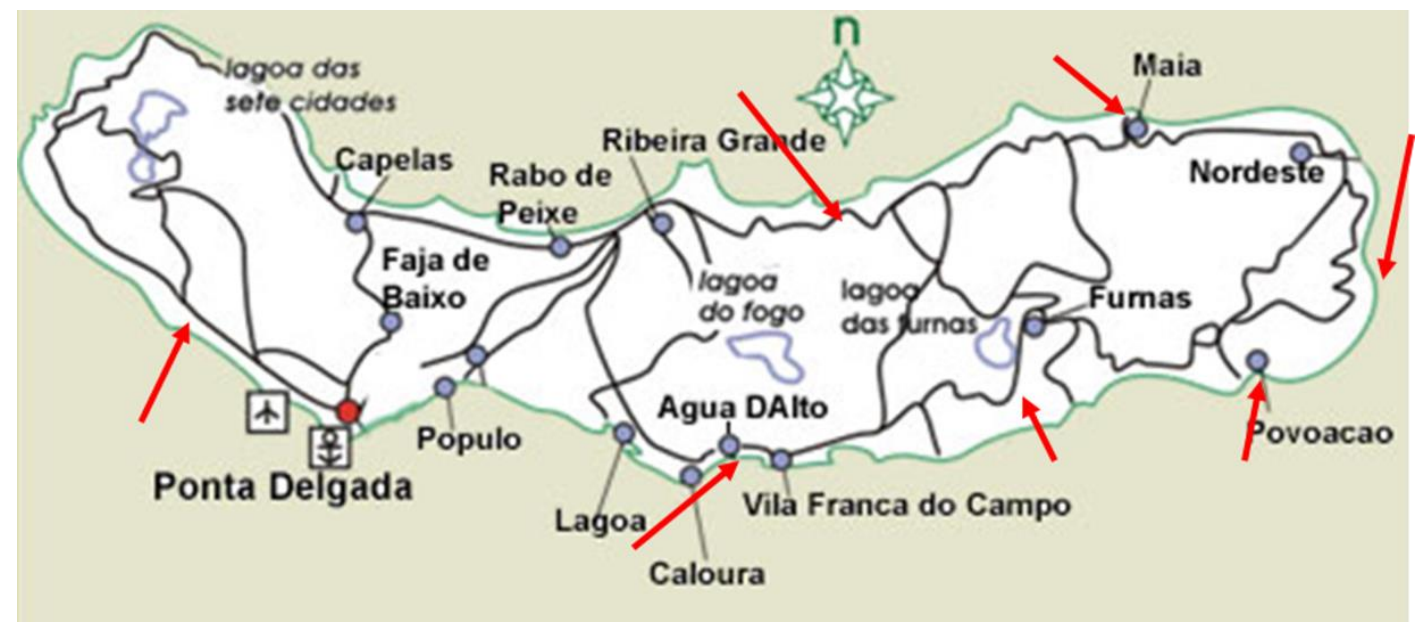

Figure 4. Potential sites in the island of São Miguel (indicated by red arrows) for large-scale energy storage using PHES.

In this context, the use of an SPS system is particularly suitable for São Miguel, minimizing the costs involved in the project due to the construction of a single reservoir. Using electricity as the energy carrier, the energy storage system proposed in this work is a supply-side technology related to the infrastructure of the electricity grid, according to the classification scheme in [38]. As already pointed out, the most typical application of PHES systems is the storage of energy generated at low incremental cost during off-peak hours, and the return of this energy to the load during peak hours, thus successfully replacing the energy generated at high incremental cost. With regard to São Miguel, the load curves in Figure 3 clearly show that energy could be stored during the nights in order to be used later on during the day. Furthermore, given the differences between weekends and weekdays, energy could also be stored on Saturdays and Sundays for use during the week. The main assumptions on the techno-economic parameters of the storage technology considered in this work are summarized in Table 2 [18].

Table 2. Cost factors and efficiency of new energy storage plant.

\begin{tabular}{ccccc}
\hline Technology & Investment Costs $(\boldsymbol{\ell} / \mathbf{k W})$ & Fixed Costs $(€ / \mathbf{k W})$ & Variable Costs $(€ / \mathrm{GJ})$ & Efficiency \\
\hline SPS & 2000 & 46 & 0.1 & $72 \%$ \\
\hline
\end{tabular}

\subsection{Overview of Transportation Sector in São Miguel}

According to the available data for 2007, the transportation sector in São Miguel accounts for the $49.2 \%$ of the final energy consumption. The total number of vehicles in the fleet is 54,221 , presenting an increasing trend on an annual basis from 2003 to 2007, as shown in Figure 5 for light-duty vehicles (LDVs), high-duty vehicles (HDVs), two-wheelers (2Ws), and others. The average mobility in São Miguel corresponds to $9478 \mathrm{~km} /$ year (or $26.0 \mathrm{~km} /$ day) and 15,446 km/year (or $42.3 \mathrm{~km} /$ day) for gasoline and diesel cars respectively. These figures indicate that the use of EDVs is especially attractive in the case of São Miguel [24] and, thus, are taken into consideration in the scenarios examined in this work. 


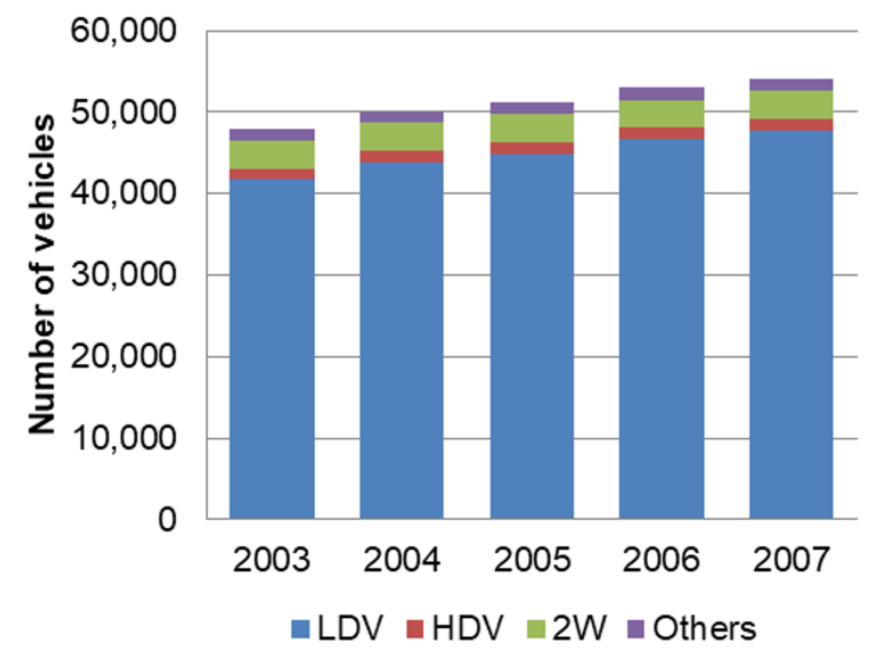

Figure 5. Composition of vehicle fleet in São Miguel, from 2003 to 2007.

\section{Methodology}

\subsection{Energy Systems Modeling Tool}

The implementation of an SPS facility, whether in the presence of EDVs or not, is expected to have a significant impact on the electricity generation sector in São Miguel, hence, TIMES was chosen as an energy analysis tool capable of representing the local energy system with sufficient level of detail and over multiple periods. Specifically, TIMES is an equilibrium-based investment optimization tool that finds the best configuration of the energy system for each time period by selecting the set of supply and demand side technologies (among the available options) that minimize the total discounted system cost. TIMES has been developed and maintained by the Energy Technology System Analysis Programme (ETSAP) under the auspices of the International Energy Agency (IEA) as a bottom-up model generator that employs a techno-economic approach to determine the optimal-cost configuration of local, national or multi-regional energy systems over medium to long-term time horizons [39].

The energy markets in TIMES are competitive and the participating agents have perfect foresight of the present and future market's parameters in the sense that the evolution of demands, attributes of the technologies (e.g., techno-economic data) and energy carriers needed to serve these demands are known, thus market manipulation is precluded. The economy in TIMES is based on the property of supply-demand equilibrium, where for each commodity the quantity produced by suppliers equals the quantity demanded by consumers and its market price equals its marginal value. In this context, TIMES generates a partial equilibrium model, including only the relevant parts of the economy, e.g., the energy sector, and computes the energy flows and commodity prices at the point of equilibrium that maximizes the total surplus of suppliers and consumers or equivalently minimizes the total system cost [39]. To this end, the generated TIMES takes into account the total lifetime costs of the competing technology alternatives along with the constraints imposed on the system, such as limits on resource availability, potential market penetration of technologies and emission caps [40]. The total system cost includes all the relevant cost factors summed up over the entire time horizon, as shown in Equation (1) [41]:

$$
C_{t o t}=C_{i n v}+C_{s u n}+C_{f i x}+C_{v a r}+T+C_{s u r}+C_{d e c}-S-M-V
$$

where $C_{\text {tot }}, C_{i n v}, C_{\text {sun }}, C_{f i x}$, and $C_{\text {var }}$, are the total, investment, sunk material, fixed, and variable costs, respectively, $T$ is the taxes, $C_{\text {sur }}$ is the surveillance costs, $C_{d e c}$ is the decommissioning costs, $S$ is the subsidies, $M$ is the recuperation of sunk material costs, and $V$ is the salvage value.

To determine the configuration of the energy system that satisfies all the requirements of the supply-demand equilibrium model at least cost over the multiple periods of the time horizon, 
decisions on equipment investment and operation, primary energy supply and energy trade are made simultaneously, according to Equation (2) [39]:

$$
N P V=\sum_{r=1}^{R} \sum_{y \in Y E A R S}\left(1+d_{r, y}\right)^{R E F Y R-y} * \operatorname{ANNCOST}(r, y)
$$

where NPV is the net present value of the total costs, ANNCOST is the total annual cost, $d$ is the general discount rate, $R$ is the set of regions under study, REFYR is the reference year for discounting, and YEARS is the set of years for which costs occur.

\subsection{Reference Energy System (RES) of São Miguel}

The present work employs the demand-driven and technology-oriented approach of the TIMES framework to model the energy system of São Miguel over a medium-term time horizon. The high-level representation of the reference energy system (RES) of São Miguel in Figure 6 shows the currently available (boxes with red outline) and possible future energy technologies (boxes with blue outline), as well as energy carriers for the purposes of this study. Given that the energy economy in TIMES consists of producers and consumers of commodities (e.g., energy carriers, materials, energy services, and emissions), competitive markets are assumed for all commodities in the TIMES model of São Miguel, resulting in a supply-demand equilibrium that maximizes the net total surplus [39]. The demand side of the model consists of specific (disaggregated) energy service demands for agriculture, industry, services and commerce, domestic sector, and transportation, while the supply side of the model includes both renewable and non-renewable energy sources, i.e., hydro, wind, geothermal, and oil. The techno-economic parameters of the competing supply side technologies include capacity, energy efficiency, availability factor, lifetime, capital costs, as well as fixed and variable operating costs, and the model chooses among them in order to meet the sectoral energy demands at minimum system cost, based on the assumptions made on the energy prices, resource availabilities and energy trade. The relevant data regarding model parameters and assumptions are obtained from the several studies made for the government of Azores [42].

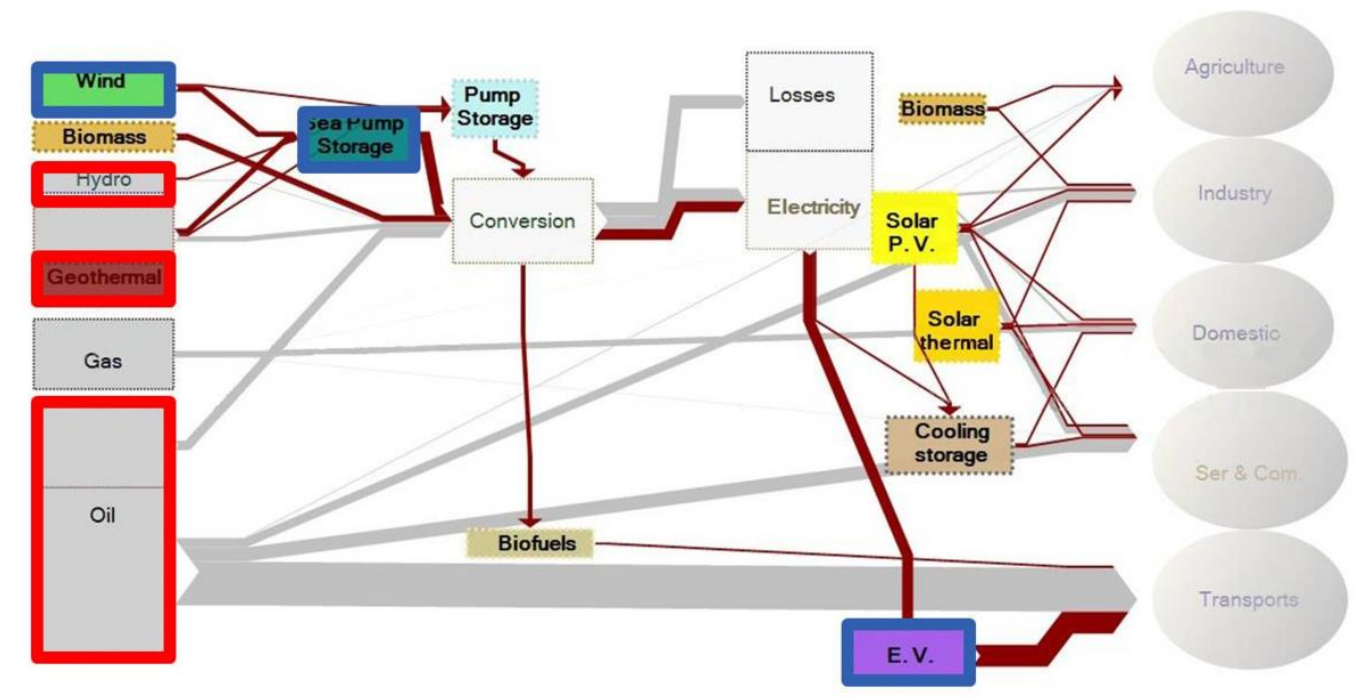

Figure 6. High-level representation of RES of São Miguel.

\subsection{Future Trends and Scenarios}

Taking into consideration that the work in [18] examines the case of implementing an SPS system in São Miguel under different fuel prices and growth rates of electricity consumption, this paper focuses on the effect of combining the implementation of an SPS system with the deployment of EDVs 
in local energy system. To that end, the following six scenarios are examined in the frame of this work: Scenarios 1-3 consider different levels for the deployment of EDVs without storage facilities, i.e., $0 \%$, $32 \%$, and $4 \%$ for scenarios 1,2 , and 3, respectively, while scenarios 4-6 consider different strategies for the deployment of EDVs under the presence of the SPS system, namely no EDVs in scenario 4, direct deployment of EDVs in scenario 5, and gradual deployment of EDVs in scenario 6. At this point, it is noted that all scenarios assume a constant fuel price and growth rate of consumption.

Relevant studies on the evolution of electricity consumption in São Miguel showed an annual increase of $6.6 \%$, followed by a lower increase rate in the next years [43]. In this context, the baseload scenario of the present work considers an annual consumption growth of $4 \%$ from the year 2007 until 2020.

Table 3 provides some key characteristics of power plants that can be potentially built to cover the anticipated demand. Specifically, the installed capacity of geothermal plants has the potential to almost double in the next years, given that the maximum capacity of geothermal energy is estimated at approximately $46 \mathrm{MW}$. Moreover, the replacement of existing hydro turbines with new ones due to ageing reasons could additionally increase the electricity production from hydro energy. As a result of the high wind potential in São Miguel, the installed capacity of onshore wind generators can reach a maximum of roughly $58 \mathrm{MW}$ [44], having a capacity factor in the range of $\sim 35-40 \%$. Off-shore wind generators provide an alternative yet more expensive option, since they have comparable capacity factors, but higher cost. Based on the assumptions about the cost of relevant technologies given in [45], the variable and fixed costs considered for the purposes of the present work are summarized in Table 4 . At this point, it is noted that the investment costs for the electricity generation technologies in Table 3 are adjusted to the values of previous investments in the Azores islands.

Table 3. Characteristics of new power plants.

\begin{tabular}{cccc}
\hline Energy Source & Investment Cost $(\boldsymbol{\epsilon} / \mathbf{k W})$ & Capacity Factor & Maximum Capacity (MW) \\
\hline Fuel oil & 1000 & $90 \%$ & - \\
Geothermal & 2500 & $85 \%$ & 23 \\
Small hydro & 2000 & $32 \%$ & 8 \\
Wind & 1600 & $35 \%$ & 178 \\
Solar & 5500 & $20 \%$ & - \\
\hline
\end{tabular}

Table 4. Fixed and variable costs of new power plants.

\begin{tabular}{ccc}
\hline Energy Source & Fixed Costs $(\boldsymbol{\epsilon} / \mathbf{k W})$ & Variable Costs $(\boldsymbol{\epsilon} / \mathbf{G J})$ \\
\hline Fuel oil & 9 & 0.32 \\
Geothermal & 63 & 0.10 \\
Small hydro & 23 & 0.10 \\
Wind & 28 & 0.10 \\
Solar & 41 & 0.10 \\
\hline
\end{tabular}

Table 5 shows the main characteristics of the six scenarios examined in this work, under the assumption that the price of fuel oil remains constant and equal to the level of 2007, i.e., $0.362 € / \mathrm{kg}$. Specifically, the existing situation, or Scenario 1, is further described in the form of scenario phases in Table 6, containing initially only the capacity from existing renewable energy sources in 2007, namely $24 \mathrm{MW}$ of geothermal and $5 \mathrm{MW}$ of hydro power (Business-as-Usual (BAU)). There is also the Electricidade dos Açores (EDA) plan (until year 2013-Scenario 4) for the further enhancement (51 MW) of the island in green energy, while there is the simulation of this plan with further steps proposed by the authors: addition of a $10 \mathrm{MW}$ geothermal (Geo3) power plant, 32\% of EDVs for the years 2013 and 2020 and an SPS system of 10 MW denoted by Scenarios 2, 3, 5, and 6. The difference between Scenarios 5 and 6 is that the former considers the direct deployment of $32 \%$ of EDVs in 2020, 
while the latter assumes a gradual deployment of EDVs, starting from a penetration level of $4 \%$ in 2013 and following a linear increase over the years to reach the value of 32\% in 2020.

Table 5. Main characteristics of the scenarios.

\begin{tabular}{ccccc}
\hline Scenario & $\begin{array}{c}\text { Consumption } \\
\text { Growth Rate }\end{array}$ & $\begin{array}{c}\text { Storage } \\
\text { Availability }\end{array}$ & $\begin{array}{c}\text { Fuel Price in } \\
\mathbf{2 0 0 8}(\boldsymbol{\epsilon} / \mathbf{k g})\end{array}$ & $\begin{array}{c}\text { Capacity of Renewable } \\
\text { Energy Sources (MW) }\end{array}$ \\
\hline 1 & $4.0 \%$ & No & 0.362 & 29 \\
2 & $4.0 \%$ & No & 0.362 & $51+32 \%$ EDVs in 2013 \\
3 & $4.0 \%$ & No & 0.362 & $51+4 \%$ EDVs in 2013 \\
4 & $4.0 \%$ & Yes & 0.362 & $51+$ No EDVs \\
5 & $4.0 \%$ & Yes & 0.362 & $51+32 \%$ EDVs in 2020 \\
6 & $4.0 \%$ & Yes & 0.362 & $51+32 \%$ EDVs gradually until 2020 \\
\hline
\end{tabular}

Table 6. Deployment of technologies over time in the scenario phases.

\begin{tabular}{|c|c|c|c|c|c|c|}
\hline \multirow{2}{*}{ Scenario Phase } & \multicolumn{6}{|c|}{ Year of Investment } \\
\hline & 2007 & 2010 & 2011 & 2013 & 2013 & 2013 \\
\hline BAU & $29 \mathrm{MW}$ & & & & & \\
\hline+ Geo & & (1)-3 MW & & (2)-10 MW & & (3)-10 MW \\
\hline+ Wind & & & $9 \mathrm{MW}$ & & & \\
\hline+ EDVs & & & & & $-/ 4 \% / 32 \%$ & \\
\hline+ SPS & & & & & $10 \mathrm{MW}$ & \\
\hline Total capacity of renewable energy sources & $29 \mathrm{MW}$ & $32 \mathrm{MW}$ & $41 \mathrm{MW}$ & $51 \mathrm{MW}$ & $51 \mathrm{MW}$ & $61 \mathrm{MW}$ \\
\hline
\end{tabular}

\section{Results and Discussion}

Considering that the SPS system is installed in 2013, the results obtained from the TIMES model indicate that the use of this technology is at its peak in the first year of its introduction to the local energy system, as shown in Figure 7. Moreover, there is a slightly higher use of the storage system when there are no EDVs (Scenario 4) compared to the case of deploying EDVs in the local vehicle fleet (Scenario 6). The electricity supply from the SPS system is gradually decreasing in both cases, yet with different slopes (and thus percentages) as denoted by the different trends observed in Figure 7 until 2017. The use of the storage system is at a minimum level in 2017, after which it starts rising again. The reason is that, in this year, there is a shutdown of one of the fuel power plants, resulting in less excess electricity to be fed in the SPS system, while there is a necessity to use the storage system once again to a greater extent in the following years. Once this power plant is off, the use of energy storage in both scenarios fluctuates to a lesser extent and finally converges to the same value with that of the year 2020.

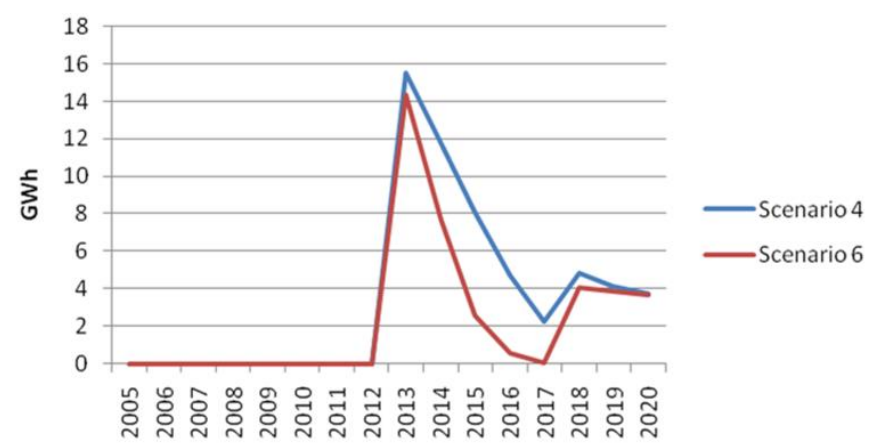

Figure 7. Annual electricity production from SPS for Scenarios 4 and 6.

Then, a comparison between the six scenarios is performed, in order to evaluate the most favorable conditions for the use of SPS. At this point, it is noted that all scenarios in this work assume a constant fuel price, even though previous studies have shown the significance of this factor [18].

Based on the load profiles in Figure 3, the results obtained from Scenarios 1, 2, 3, and 4 are compared in Figures 8 and 9. As expected and has been shown also in earlier relevant studies [21,24], 
the introduction of EDVs as a G2V energy consumption source in 2013, along with the instantaneous penetration of the new geothermal power plant, results in significant fuel reduction of around $10 \%$, although in the present study this depends on the percentage of the EDV penetration (4\% or 32\%) yet without presenting great differences in their rates. This significant reduction is accompanied by an increase in the percentage (58\%) of renewable energy sources in the electricity supply as also expected. In Scenario 4, which refers to the introduction of the SPS system without the presence of EDVs, the storage provided by this system reduces further $(\sim 3 \%)$ the fuel consumption, and as also observed in Scenarios 2 and 3, the key finding is that it increases significantly the renewable energy sources penetration in the electricity mix, reaching the percentage of $71 \%$. Moreover, the energy that is pumped and then discharged directly in the system (energy mix) reaches a high value of $72.3 \%$ in Scenario 4.

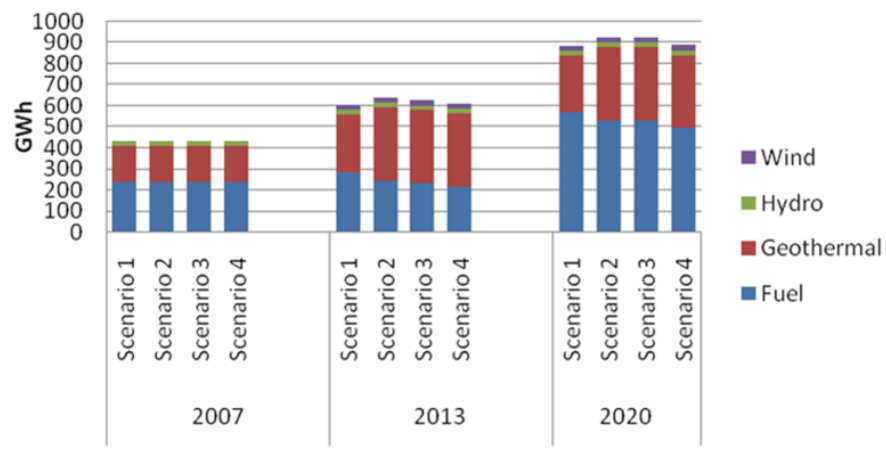

Figure 8. Scenarios 1, 2, 3, and 4: Electricity supply in absolute values.

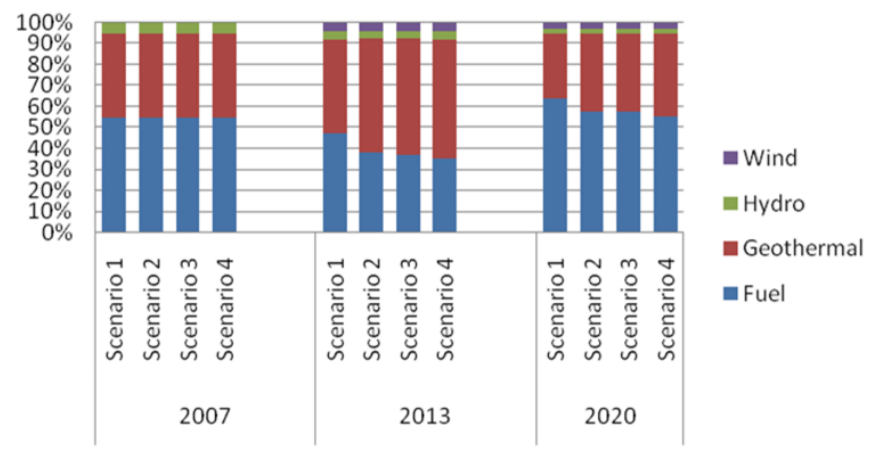

Figure 9. Scenarios 1, 2, 3, and 4: electricity supply in percentage terms.

A first indication by the comparison of these scenarios is that the penetration of EDVs can be enhanced by the introduction of the new geothermal plant, which acts as a baseload, while reducing the fuel significantly and also bringing the corresponding environmental benefits. At this point, it is noted that if the EDVs were applied as a V2G source in the energy system, it would be interesting to examine how the energy storage from the EDV batteries would perform in terms of providing the necessary electricity back to the grid, while a higher penetration rate would be expected for the renewables. The storage capacity provided by the SPS acts also very efficiently and has a significant impact on the reduction of fuel consumption $(-12.6 \%)$ with increased penetration rates of the new renewable energy technologies used, ranging from $58 \%$ to $71 \%$.

Regarding the use of renewable energy in the island in 2020, Figures 10 and 11 show that Scenarios 4,5 , and 6 once again enable a high penetration percentage (ranging from $38 \%$ to $48 \%$ ). However, in this case it is well below compared to the year 2013 and it is after that year that a continuous decline is observed for the scenarios. In a first instance, it might be observed that SPS and EDVs behave competitively against each other, but this is clearly due to the increase in demand, which is not accompanied by an increase in fuel prices that would enable the use of more renewable energy technologies, as well as that of the storage system. Therefore, the two systems can coexist without 
creating any problems to the grid. The comparison of the direct deployment of EDVs in Scenario 5 with the gradual penetration of EDVs from 2013 to 2020 (Scenario 6) shows that both scenarios result in the same penetration level of renewable energy sources in 2020. However, it should be noted that the small percentage (4\%) of EDVs in the year 2013 for scenario 6 makes feasible a higher percentage of renewable energy sources compared to scenario 5.

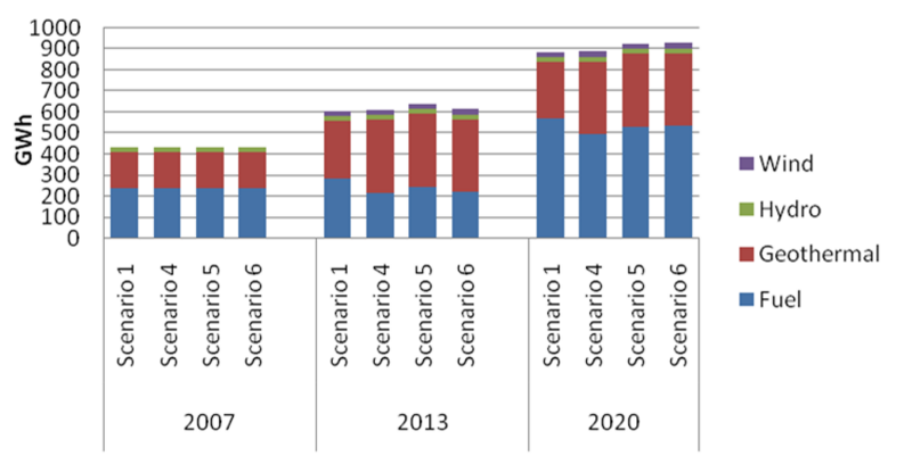

Figure 10. Scenarios 1, 4, 5, and 6: Electricity supply in absolute values.

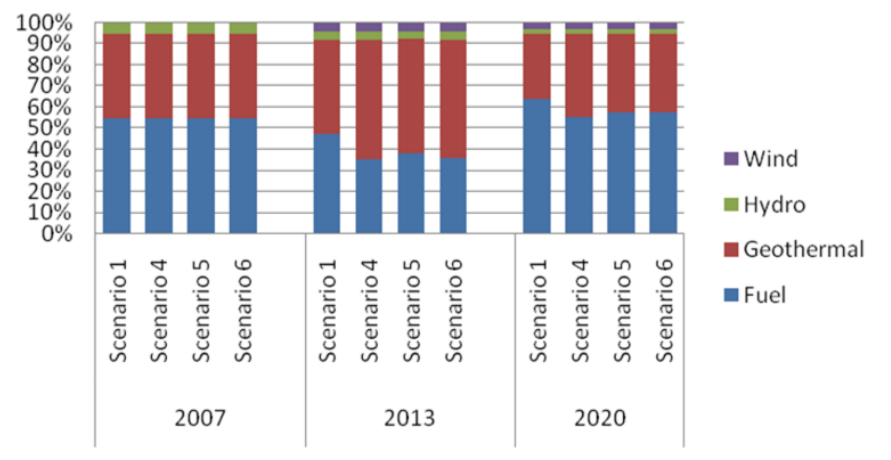

Figure 11. Scenarios 1, 4, 5, and 6: electricity supply in percentage terms.

This work examines different cases, i.e., with or without energy storage from an SPS system under different levels and strategies of EDVs deployment, assuming a constant growth rate of electricity demand and a fixed fuel price. The effect of these two parameters for an SPS system in São Miguel (without the presence of EDVs) has been analyzed by the authors in [18]. In the light of this study, it is noted that the increase of fuel prices favors the use of renewable energy sources, i.e., increases the penetration of renewable energy sources, as well as the use of the SPS system. For example, high fuel prices make expensive wind turbines more competitive. On the other hand, it is also observed that the higher growth rate of electricity demand does not necessarily mean higher use of the SPS system under low fuel prices.

\section{Conclusions}

This work presents a number of scenarios for the island of São Miguel with the aim to provide some useful insight into the potential impact of an SPS system on the local energy system. The analysis of the scenarios indicates that the implementation of the storage system would have multiple benefits for the island. In detail, it would allow the increase of renewable energy use, thus lowering the imports of fuels, as intermittent energy sources could be used more reliably. Furthermore, given the large differences between peak and off-peak electricity consumptions, combined with the large geothermal and wind potential in the island, energy could be stored in times of low demand for later use. At a first glance, three possible storage cycles are available: seasonal, weekly, and daily. The two most important ones are the weekly and daily cycles. The weekly cycles would store energy during the weekends to 
use it later on during the week, while the daily cycles would store during the nights to use during peak hours.

Moreover, the scenario results showed that with the fuel prices under study an SPS system would benefit the further penetration of renewables. Even in the presence of EDVs under a G2V scheme, the system would still permit to have a high penetration of renewables though not as high as before, but the environmental benefits would be particularly significant, while substituting a large number of internal combustion engine vehicles and without presenting any problems in the grid.

Concluding, this paper analyzes the electricity dynamics and builds upon the expected demand growth rates and fixed fuel prices to establish the scenarios under study. No assumption or further analyses were made on a possible future increase of fuel prices that would certainly benefit further the use of the SPS system. Thus, future work could study the impact of fluctuations in fuel prices or how the halt of consumption growth would influence the use of energy storage, as well as on sensitivity analyses to verify the robustness of the results.

Author Contributions: Both authors have worked on this manuscript together and have read and approved the final manuscript.

Funding: This work was supported by FCT (Fundação para a Ciência e a Tecnologia) under Grant MIT-Pt/SES-GI/008/2008 and E.U. Seventh Framework Programme under grant 621408 (RE-SIZED: Research Excellence for Solutions and Implementation of Net-Zero Energy City Districts).

Acknowledgments: The authors would like to thank Electricidade dos Açores (EDA) for providing a large amount of data to be used in the model, as well as André Pina, Paulo C. Ferrão, and the Government of the Azores for their valuable help.

Conflicts of Interest: The authors declare no conflict of interest.

\section{References}

1. Deane, J.P.; Ó Gallachóir, B.P.; McKeogh, E.J. Techno-economic review of existing and new pumped hydro energy storage plant. Renew. Sustain. Energy Rev. 2010, 14, 1293-1302. [CrossRef]

2. Rehman, S.; Al-Hadhrami, L.M.; Alam, M.M. Pumped hydro energy storage system: A technological review. Renew. Sustain. Energy Rev. 2015, 44, 586-598. [CrossRef]

3. Teng, F.; Pudjianto, D.; Aunedi, M.; Strbac, G. Assessment of Future Whole-System Value of Large-Scale Pumped Storage Plants in Europe. Energies 2018, 11, 246. [CrossRef]

4. Renewable Energy Policy Network for the 21st Century (REN21). Renewables 2017 Global Status Report. Available online: http:/ / www.ren21.net/gsr_2017_full_report_en (accessed on 27 July 2018).

5. Kadiyala, A.; Kommalapati, R.; Huque, Z. Evaluation of the Life Cycle Greenhouse Gas Emissions from Hydroelectricity Generation Systems. Sustainability 2016, 8, 539. [CrossRef]

6. Rohit, A.K.; Devi, K.P.; Rangnekar, S. An overview of energy storage and its importance in Indian renewable energy sector: Part I-Technologies and Comparison. J. Energy Storage 2017, 13, 10-23. [CrossRef]

7. Min, C.-G.; Kim, M.-K. Flexibility-Based Reserve Scheduling of Pumped Hydroelectric Energy Storage in Korea. Energies 2017, 10, 1478. [CrossRef]

8. Rodrigues, A.; Machado, D.; Dentinho, T. Electrical energy storage systems feasibility; The case of Terceira Island. Sustainability 2017, 9, 1276. [CrossRef]

9. International Energy Agency (IEA). Technology Roadmap-Hydropower. 2012. Available online: http:/ / www.iea.org/publications / freepublications/publication/2012_Hydropower_Roadmap.pdf (accessed on 27 July 2018).

10. Merino, J.; Veganzones, C.; Sanchez, J.A.; Martinez, S.; Platero, C.A. Power System Stability of a Small Sized Isolated Network Supplied by a Combined Wind-Pumped Storage Generation System: A Case Study in the Canary Islands. Energies 2012, 5, 2351-2369. [CrossRef]

11. Katsaprakakis, D.A.; Christakis, D.G.; Stefanakis, I.; Spanos, P.; Stefanakis, N. Technical details regarding the design, the construction and the operation of seawater pumped storage systems. Energy 2013, 55, 619-630. [CrossRef]

12. Katsaprakakis, D.A.; Christakis, D.G. Seawater pumped storage systems and offshore wind parks in islands with low onshore wind potential. A fundamental case study. Energy 2014, 66, 470-486. [CrossRef] 
13. Manfrida, G.; Secchi, R. Seawater pumping as an electricity storage solution for photovoltaic energy systems. Energy 2014, 69, 470-484. [CrossRef]

14. Portero, U.; Velázquez, S.; Carta, J.A. Sizing of a wind-hydro system using a reversible hydraulic facility with seawater. A case study in the Canary Islands. Energy Convers. Manag. 2015, 106, 1251-1263. [CrossRef]

15. Hiratsuka, A.; Arai, T.; Yoshimura, T. Seawater pumped-storage power plant in Okinawa island, Japan. Eng. Geol. 1993, 35, 237-246. [CrossRef]

16. Akinyele, D.O.; Rayudu, R.K. Review of energy storage technologies for sustainable power networks. Sustain. Energy Technol. Assess. 2014, 8, 74-91. [CrossRef]

17. Kim, J.; Suharto, Y.; Daim, T.U. Evaluation of Electrical Energy Storage (EES) technologies for renewable energy: A case from the US Pacific Northwest. J. Energy Storage 2017, 11, 25-54. [CrossRef]

18. Pina, A.; Ioakimidis, C.S.; Ferrão, P. Economic modeling of a seawater pumped-storage system in the context of São Miguel. In Proceedings of the 2008 IEEE International Conference on Sustainable Energy Technologies, ICSET 2008, Singapore, 24-27 November 2008; pp. 707-712. [CrossRef]

19. Correia, P.F.; Ferreira De Jesus, J.M.; Lemos, J.M. Sizing of a pumped storage power plant in S. Miguel, Azores, using stochastic optimization. Electr. Power Syst. Res. 2014, 112, 20-26. [CrossRef]

20. Osório, G.J.; Shafie-khah, M.; Lujano-Rojas, J.M.; Catalão, J.P.S. Scheduling Model for Renewable Energy Sources Integration in an Insular Power System. Energies 2018, 11, 144. [CrossRef]

21. Kadurek, P.; Ioakimidis, C.; Ferräo, P. Electric vehicles and their impact to the electric grid in isolated systems. In Proceedings of the 2009 International Conference on Power Engineering, Energy and Electrical Drives, POWERENG '09, Lisbon, Portugal, 18-20 March 2009; pp. 49-54. [CrossRef]

22. Kadurek, P.; Ioakimidis, C. São Miguel Island as a case study on a possible usage of electric vehicle to store energy. In Proceedings of the 24th International Battery, Hybrid and Fuel Cell Electric Vehicle Symposium and Exhibition 2009, EVS 24, Stavanger, Norway, 13-16 May 2009; pp. 2442-2448.

23. Camus, $\mathrm{C}$.; Farias, T. The electric vehicles as a mean to reduce $\mathrm{CO}_{2}$ emissions and energy costs in isolated regions. The São Miguel (Azores) case study. Energy Policy 2012, 43, 153-165. [CrossRef]

24. Ioakimidis, C.S.; Genikomsakis, K.N. Introduction of plug-in hybrid electric vehicles in an isolated island system. Adv. Build. Energy Res. 2018, 12, 66-83. [CrossRef]

25. Serviço Regional de Estatística dos Açores (SREA). Azores in Figures 2005; SREA: Lisbon, Portugal, 2006.

26. Directorate-General of Energy and Geology (DGEG). Fuel Consumption 2005; DGEG: Lisbon, Portugal, 2006.

27. Electricidade dos Açores (EDA). Statistical Information-December 2007; EDA: Lisbon, Portugal, 2008.

28. Electricidade dos Açores (EDA). Characterization of the Electricity Transport and Distribution Networks of the Azores; EDA: Lisbon, Portugal, 2006.

29. Ibrahim, H.; Ilinca, A.; Perron, J. Energy storage systems-Characteristics and comparisons. Renew. Sustain. Energy Rev. 2008, 12, 1221-1250. [CrossRef]

30. Hino, T.; Lejeune, A. Pumped Storage Hydropower Developments. Compr. Renew. Energy 2012, 6, 405-434. [CrossRef]

31. Katsaprakakis, D.A.; Christakis, D.G.; Zervos, A.; Papantonis, D.; Voutsinas, S. Pumped storage systems introduction in isolated power production systems. Renew. Energy 2008, 33, 467-490. [CrossRef]

32. Pinner, D. Economics/Emerging Business Opportunities in Energy Storage; McKinsey \& Company: New York, NY, USA, 2008.

33. Ter-Gazarian, A.G. Energy Storage for Power Systems, 2nd ed.; Institution of Engineering and Technology: London, UK, 2011; pp. 1-277.

34. Martifer Renewables. Green Islands Project Report, Portugal. 2009. Available online: http://www.martifer. $\mathrm{pt}$ /en/group/institutional/contact-us/ (accessed on 27 September 2018).

35. Gagnon, L.; Bélanger, C.; Uchiyama, Y. Life-cycle assessment of electricity generation options: The status of research in year 2001. Energy Policy 2002, 30, 1267-1278. [CrossRef]

36. Fujihara, T.; Imano, H.; Oshima, K. Development of pump turbine for seawater pumped-storage power plant. Hitachi Rev. 1998, 47, 199-202.

37. Tanaka, K. Pumped-storage power plant using sea water. J. Inst. Electr. Eng. Jpn. 2004, 124, 583-586. [CrossRef]

38. Tronchin, L.; Manfren, M.; Nastasi, B. Energy efficiency, demand side management and energy storage technologies-A critical analysis of possible paths of integration in the built environment. Renew. Sustain. Energy Rev. 2018, 95, 341-353. [CrossRef] 
39. Loulou, R.; Remne, U.; Kanudia, A.; Lehtila, A.; Goldstein, G. Documentation for the TIMES-PART I. Energy Technology Systems Analysis Programme. 2005. Available online: http:/ /iea-etsap.org/docs/TIMESDocIntro.pdf (accessed on 27 July 2018).

40. Howells, M.I.; Alfstad, T.; Victor, D.G.; Goldstein, G.; Remme, U. A model of household energy services in a low-income rural African village. Energy Policy 2005, 33, 1833-1851. [CrossRef]

41. Alfstad, T. Development of a Least Cost Energy Supply Model for the SADC Region. Master's Thesis, University of Cape Town, Cape Town, South Africa, 2005.

42. Agencia Regional da Energia da Regiao Autonoma dos Açores (ARENA). Projecto ERAMAC Recursos Energéticos Endógenos Energia para os Açores; ARENA: Lisbon, Portugal, 2005.

43. Peças Lopes, J.A.; Mendonça, A.; Matos, M. Capacity Evaluation of the Introduction of Renewable Energy in the Networks of the Azores Islands; INESC-Porto: Porto, Portugal, 2004.

44. Instituto de Engenharia Mecânica e Gestão Industrial (INEGI). Potential of Wind Energy in the Azores; INEGI: Aguascalientes, Mexico, 2004.

45. Vaillancourt, K.; Labriet, M.; Loulou, R.; Waaub, J.-P. The role of nuclear energy in long-term climate scenarios: An analysis with the World-TIMES model. Energy Policy 2008, 36, 2296-2307. [CrossRef]

(C) 2018 by the authors. Licensee MDPI, Basel, Switzerland. This article is an open access article distributed under the terms and conditions of the Creative Commons Attribution (CC BY) license (http:/ / creativecommons.org/licenses/by/4.0/). 